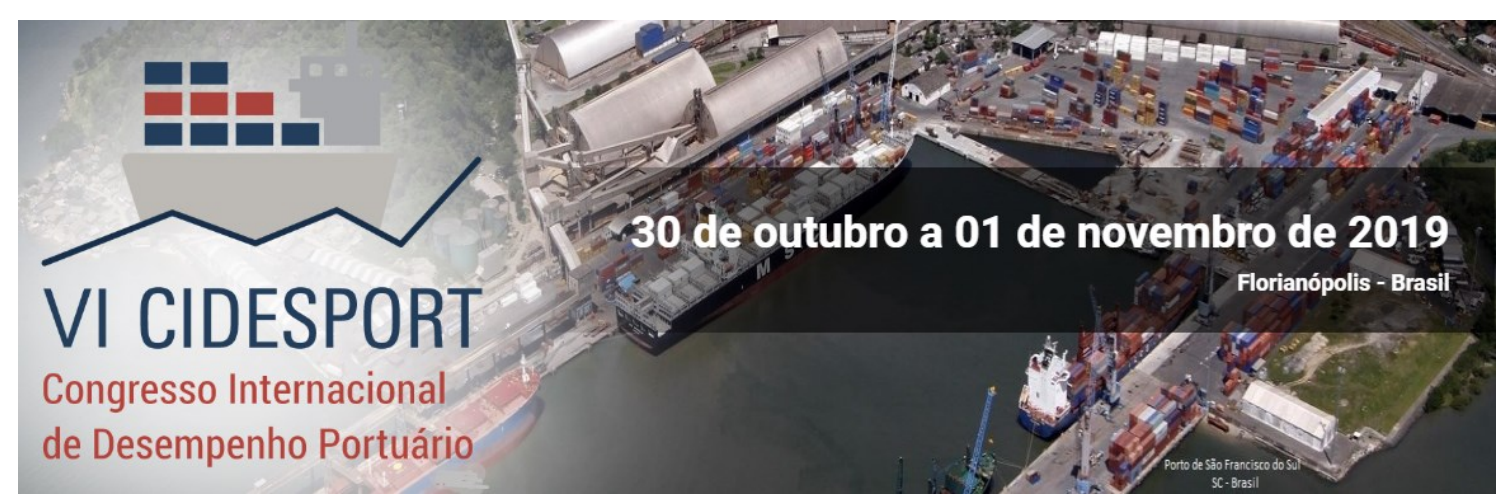

\title{
IDENTIFICAÇÃO DAS MÉTRICAS DE DESEMPENHO NA INTER-RELAÇÃO ENTRE OS AGENTES PORTO E ARMAZÉM ALFANDEGADO: UM ESTUDO NO PROCESSO DE IMPORTAÇÃO DO GRANITO PRIME
}

\author{
Leonardo Melo Delfim \\ Universidade Federal da Paraílba \\ Jonas Figuerêdo Silva \\ Universidade Federal da Paraílba \\ Pedro Henrique Monteiro da Silva \\ Universidade Federal da Paraíba \\ Maria Silene Alexandre Leite \\ Universidade Federal da Paraíba
}

Resumo: O transporte marítimo é o principal meio de interligação entre nações para o comércio internacional por meio da importação e exportação, sendo o porto instrumento essencial nesta conexão. Esta pesquisa focou-se no processo de importação da carga conteinerizada, especificamente do produto granito prime escoada por um porto do Nordeste do Brasil com o objetivo de identificar métricas de desempenho na inter-relação entre os agentes porto e armazém alfandegado. A pesquisa foi conduzida por meio de entrevistas com os agentes responsáveis pelo processo de importação do granito prime, resultando no mapeamento da cadeia do produto e no levantamento das atividades executadas pelo porto e pelo armazém alfandegado. A partir deste ponto, foi possível aplicar a abordagem logística Supply chain operations reference model (SCOR), a qual visa a melhoria da cadeia de abastecimento abrangendo as interações com o cliente, as transações de materiais físicos e as interações com o mercado. Sendo destacado neste trabalho as seções de processos e performance do modelo SCOR. Assim permitiu-se estruturar de forma sistemática as atividades executadas na cadeia do produto granito prime e proceder a identificação das métricas correspondentes.

Palavras-chave: Métricas. SCOR. Logística Portuária.

\section{INTRODUÇÃO}

O transporte marítimo é o principal meio na interligação do comércio internacional entre as nações. Segundo a Agência Nacional de Transportes Aquaviários (ANTAQ, 2019), o setor portuário brasileiro teve um crescimento de $7,22 \%$ de 2017 para 2018 na movimentação de TEUs (medida de um contêiner de 20 pés). Nos portos públicos a movimentação total de contêineres apresentou um aumento de $10 \%$ em relação a 2017 , e os portos privados o incremento de $1,50 \%$ também em relação ao ano de 2017 . Enquanto ao perfil de carga, o granel sólido

* A revisão gramatical, ortográfica, ABNT ou APA foi realizada pelos autores. 


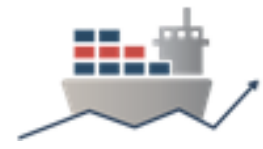

registrou um aumento de $2,4 \%$, o granel líquido $(+1,9 \%)$, contêineres $(+4,8 \%)$ e carga geral solta $(+6,1 \%)$.

Segundo Cho (2014), a globalização mudou fundamentalmente o paradigma comercial, e o setor marítimo está incluído nesse fenômeno. Juntamente com o progresso, serviços de transporte marítimos mais rápidos, mais confiáveis e mais baratos estão contribuindo para a expansão no comércio global. Para aproveitar o desenvolvimento do comércio global os países precisam remover os obstáculos que retardam a movimentação de carga através de seus portos marítimos. A carga em movimento lento resulta em altos tempos de permanência que reduzem a eficiência portuária e têm um impacto negativo no custo do comércio e na competitividade de um país (OJADI; WALTERS, 2015).

Com a expansão da economia global e logística internacional, o papel dos portos é de importância crucial para a economia nacional e regional. Os portos promovem o crescimento coordenado entre as cidades portuárias e, em geral, a economia regional, uma vez que atuam como centros de distribuição de pessoas, logística, capital, tecnologia e fluxo de informações (LIN et al., 2015). Como destacado por Silva (2018), os portos são instrumentos essenciais para as atividades de comércio exterior como a importação e a exportação, possuindo importante papel para a economia de um país e passíveis de atividades que visem sua sustentabilidade, boa gestão de recursos e custos proporcionando aumento de eficiência e desempenho.

Os processos de importação e de exportação são extremamente dinâmicos e as empresas que se relacionam com estes processos devem buscar a redução em seus custos e alternativas que viabilizem novas opções de escolha no mercado (MILAN; VIEIRA, 2011). Desta forma Santos e Villavicencio (2018), enfatizam que para se alcançar eficiência e qualidade logística se faz necessário uma avaliação constante de todo o processo, a fim de se detectarem falhas ou se a atividade em questão não adiciona valor considerável.

Segundo Krasnodębski e Kubon (2010), os custos de logística constituem um critério quantitativo básico da eficiência e modernidade dos processos logístico sendo estes de muita importância identificá-los com precisão e especificá-los detalhadamente de acordo com as necessidades. Para Alvarez-SanJaime et al. (2013), os custos logísticos também impactam no crescimento econômico, elevados custos dessa natureza podem levar a uma redução nos investimentos, menores níveis de exportação, acesso reduzido a tecnologia e conhecimento e a aumento do desemprego.

Assim Moreira (2017), ressalta que é importante que se tenha conhecimento da cadeia logística do processo portuário a ser estudado, além das atividades desempenhadas ao longo da cadeia, de forma que se torne possível visualizar todas as inter-relações entre os agentes envolvidos e identificar possíveis problemas presentes ao seu decorrer. Desse modo Leite et al. (2015), conclui que é de suma importância que os portos possuam ferramentas para identificar, apurar e mensurar os custos logísticos para que busquem competitividade.

Nesse trabalho a cadeia do produto estudada foi a da carga conteinerizada, especificamente a do granito prime, uma rocha com alto grau de dureza e muito utilizado em ambiente internos, importada da China. A escolha dessa carga ocorreu em razão da disponibilidade de dados e da devida permissão dada pelo agente trading para o estudo desta, bem como a eficiência do porto onde a citada carga é escoada. A trading é responsável por toda gestão da importação do granito prime. Assim, os principais agentes participantes nessa importação são: a empresa importadora, que 


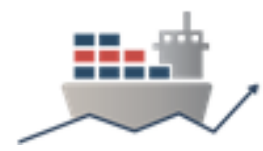

trabalha com o beneficiamento de rochas ornamentais, a trading, já citada, o agente de carga, responsável pelo transporte marítimo da carga, o porto, que opera a descarga do navio, e o armazém alfandegado, que oferece espaço de armazenagem enquanto a carga é nacionalizada.

Com a cadeia do produto mapeada, foi necessário a aplicação de uma abordagem logística que auxilia na análise do processo de importação. Segundo Medeiros (2018), o Modelo de referência de operações da cadeia de suprimentos (SCOR), é reconhecido como uma ferramenta eficiente e versátil para ser aplicada com o intuito de apoiar o método de custeio. E Spina et al. (2016) o aplica com a intenção de melhorar processos e ter base para o levantamento de indicadores e melhoria de práticas de gestão. Diante disso, nesta pesquisa aplica-se o SCOR do primeiro ao terceiro nível de processos e a seção de performance, com o objetivo de identificar métricas de desempenho na inter-relação dos agentes porto e armazém alfandegado.

\section{LOGÍSTICA PORTUÁRIA}

O transporte de mercadorias é uma indústria complexa, à medida que as cadeias de abastecimento se prolongam entre países, mares e continentes. A presença de infraestrutura necessária combinada com operações e serviços de qualidade determina o sucesso das cadeias de abastecimento internacionais. $O$ comércio marítimo internacional vem aumentando constantemente nas últimas décadas passando de 3.7 bilhoes de toneladas em 1980, 4 bilhões de toneladas em 1990, 6 bilhões toneladas no ano 2000, 8,4 bilhões de toneladas em 2010 ((CLOTT; HARTMAN, 2016); (ALVAREZ-SANJAIME et al., 2015)) e 10.7 bilhões de toneladas em 2018 (UNCTDA, 2018). Neste contexto a logística apresenta-se como atividade de grande importância no cenário atual, representando uma importante fonte de crescimento econômico e um campo que oferece potencial de oportunidades de negócios. A atividade logística é um dos elementos-chave para a garantia do aumento da satisfação e nível de atendimento ao cliente (KE, 2014).

O Council of Supply Chain Management Professionals (CSCMP, 2013) define logística como o processo de planejar, executar e controlar o fluxo e armazenagem, de forma eficaz e eficiente em termos de tempo, qualidade e custos, de matéria primas, materiais em elaboração, produtos acabados e serviços, cobrindo desde o ponto de origem até o ponto de consumo, com objetivo de atender aos requisitos do consumidor.

A logística marítima tem sido reconhecida como uma disciplina emergente, atendendo às crescentes e variadas demandas dos carregadores e à rápida mudança do papel dos navios e dos portos no contexto das cadeias de abastecimento globais. Os portos modernos operam em um ambiente de transporte e logística cada vez mais complexo e sofisticado, integrado em regimes de planejamento multi-escalar (CANON; FERRARI; PAROLA, 2015), e muitas vezes realizando atividades que agregam valor aos produtos que trafegam por eles (CASCHILI; MEDDA, 2015).

Os três principais componentes da logística portuária são os portos, os agentes de carga e as frotas de navios. Cada um deles realizam atividades essenciais para o funcionamento adequado da logística marítima, as frotas têm como função principal a movimentação das mercadorias de um porto a outro, elas também realizam atividades secundárias como prover informações de localização das mercadorias, entrega de fatura e outros serviços auxiliares. Os portos são responsáveis pelo carregamento e 
descarregamento dos navios e realiza a preparação para a carga ser entregue ao seu destino através dos modais terrestres. Outras atividades secundárias incluem o armazenamento e empacotamento. Os agentes de carga são pessoas físicas ou jurídicas envolvidas no processo de transporte marítimo, eles são responsáveis pela reserva dos navios e pela documentação necessária para o transporte de carga (SONG; PANAYIDES, 2015).

A venda é o gatilho para o início das operações logísticas. A primeira delas é o transporte interno. Esse translado é efetuado até uma alfândega, onde serão realizadas todas as etapas do processo de desembaraço aduaneiro para a exportação. Em sequência, a mercadoria é encaminhada para um porto onde embarcará para zona alfandegada diretamente ao país de destino. Ao chegar ao país, é recepcionado e feita a nacionalização, após essa etapa, tem-se o transporte interno que levará a mercadoria até o local de destino (SOUZA; SOUZA, 2013). Uma representação gráfica da logística genérica para o transporte internacional de mercadorias pode ser observado na Figura 1.

Figura 1 - Fluxo logístico Exportação / Importação

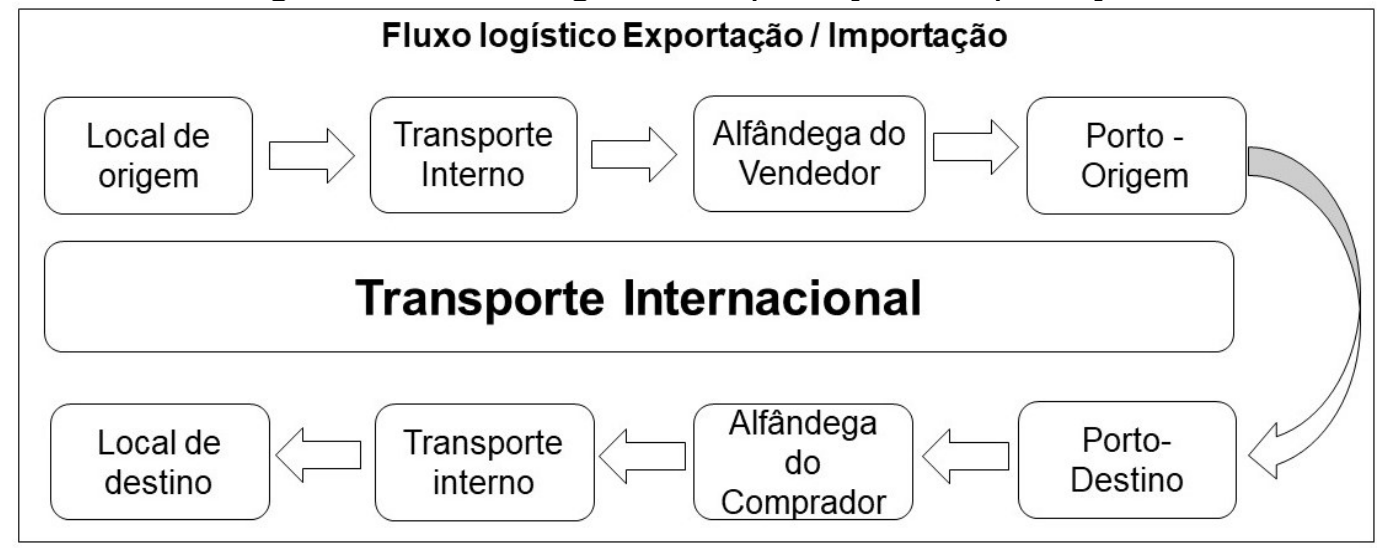

Fonte: Adaptado de (SOUZA; SOUZA, 2013)

Inicialmente, de acordo com Souza e Souza (2013), no local de origem ocorre, a embalagem, acondicionamento e expedição. Tanto no país de origem quanto no de destino, no transporte interno ocorre a cobrança do frete referente ao mesmo, na alfândega de origem/destino, há o armazenamento da mercadoria, despacho aduaneiro, impostos e taxas, no porto de origem/destino, ocorre também o armazenamento da mercadoria, capatazia e taxas referentes a operação. $\mathrm{Na}$ transferência da mercadoria, ou seja, no transporte internacional, há a cobrança do frete e do seguro de cargas, e por fim, na chegada ao local de destino, o desembarque da mercadoria e a conferência da mesma.

\section{MODELO DE REFERÊNCIA DE OPERAÇÕES DA CADEIA DE SUPRIMENTOS (SCOR)}

O SCOR, é um método de análise de gestão de cadeias de suprimentos, baseado no que foi proposto pelo Council of Supply Chain Management (SCC), sendo um padrão para o modelo de avaliação de Cadeias de Suprimentos, o qual fornece uma estrutura exclusiva que pode ser usado para mapear, avaliar e melhorar as operações da cadeia de suprimentos. 


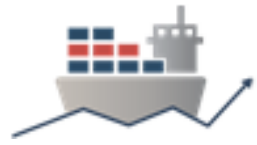

Conforme exposto por Silva (2019), diversas ferramentas e abordagens podem ser utilizadas para se analisar uma cadeia de suprimentos, a depender do objetivo o qual se quer alcançar com a análise e o tipo de informações disponíveis a respeito da cadeia. De acordo com o autor, o SCOR é recomendado quando se deseja conclusões de natureza mais estratégicas, muitas vezes para dar aporte à criação de indicadores e se tem à disposição dados qualitativos advindos de observações ou percepção de pessoas.

$\mathrm{Na}$ literatura, diversos trabalhos são encontrados nos quais o SCOR é aplicado visando os objetivos descritos. Astuti et al. (2016) aplica o SCOR com o objetivo de se levantar e analisar os riscos em uma cadeia de suprimentos, Anggrahinia et al. (2015) analisa os problemas de qualidade de forma qualitativa ao longo de uma cadeia de suprimentos de camarão, Bukhoria et al. (2015) utiliza o SCOR combinado com outros métodos para a análise de problemas de qualidade ao longo da cadeia de suprimentos de carne, Pontes et al. (2018), aplica o modelo para encontrar uma melhor execução das operações internas de um centro de distribuição visando a redução de erros e melhorias do processo e Silva et al. (2015) utiliza o SCOR com o intuito de mapear toda a cadeia produtiva de uma loja de serviços, destacando a padronização de métricas de desempenho da cadeia, utilização de técnicas de benchmarking e melhores práticas para priorizar atividades.

Segundo a Apics (2017), o modelo SCOR pode descrever um conjunto complexo de definições de setores diferentes, de modo a utilizar o modelo como suporte para projetos de melhoria da cadeia de suprimentos. O SCOR abrange todas as interações do cliente, todas as transações de materiais físicos e todas as interações de mercado. O modelo apresenta 4 seções principais, apresentadas a seguir.

\section{Quadro 1 - Seções do SCOR}

\begin{tabular}{|l|}
\hline \multicolumn{1}{|c|}{ Seções principais do SCOR } \\
\hline Práticas: Práticas de gerenciamento que produzem um desempenho de \\
processo significativamente melhor.
\end{tabular}

Fonte: Adaptado de APICS (2017)

A seção de práticas fornece uma coleção de práticas reconhecidas por empresas dos três setores da indústria (Agricultura, manufatura e serviços). Enquanto na seção de pessoas, fornece um padrão para descrever as habilidades necessárias para executar tarefas e gerenciar processos. A seção de performance é uma abordagem para entender, avaliar e diagnosticar o desempenho da cadeia de suprimentos, no qual consiste em: atributos de performance, utiliza-se para priorizar e alinhar o desempenho da cadeia de suprimentos com a estratégia de negócio, métricas, que são medidas de desempenho e a maturidade do processo/prática, utiliza descrições como ferramenta para avaliar os processos e práticas da cadeia de suprimentos (APICS, 2017).

Por fim na seção de processos, de acordo com APICS (2017), há um conjunto de descrições de atividades executadas na maioria das empresas de modo a cumprir 
VI CIDESPORT/2019

Congresso Internacional

de Desempenho Portuário

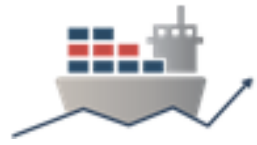

sua cadeia de suprimentos. Na Figura 2, visualiza-se de modo abrangente como é modelo referente a processos.

Figura 2 - Estrutura do modelo SCOR - Processos
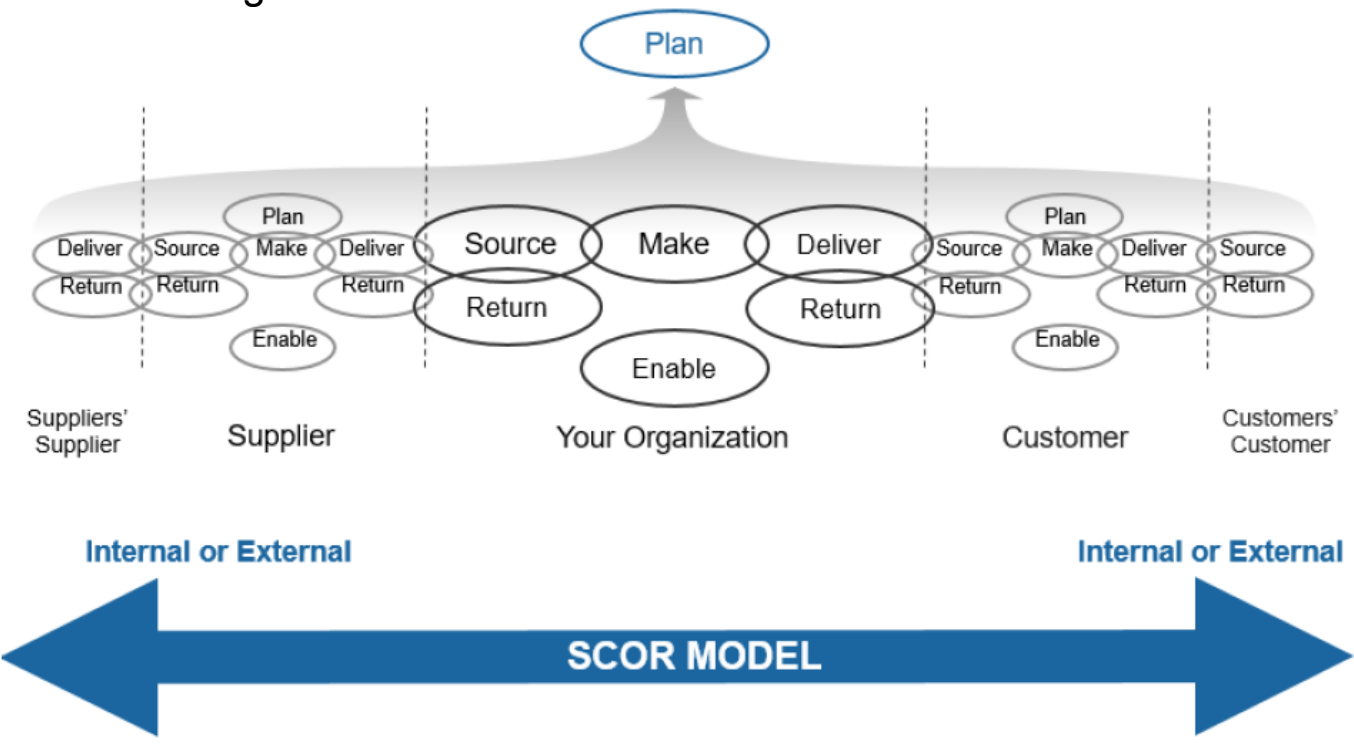

Fonte: APICS (2017)

Neste há três níveis hierárquicos básicos que o modelo SCOR fornece, no seu primeiro nível hierárquico, contêm os seguintes processos: Plan (planejar); Source (abastecer); Make (fazer); Deliver (entregar); Return (retornar); Enable (habilitar). Estes são os processos principais, no qual define-se o escopo, o conteúdo e as metas de desempenho da cadeia de suprimentos. No Quadro 2, fez-se uma breve descrição de cada um.

Quadro 2 - Primeiro nível de processos

\begin{tabular}{|c|l|c|}
\hline $\begin{array}{c}\text { PLAN } \\
\text { (Planejar) }\end{array}$ & $\begin{array}{l}\text { Os processos associados à determinação de requisitos e ações corretivas } \\
\text { para atingir os objetivos da cadeia de suprimento. }\end{array}$ \\
\hline $\begin{array}{c}\text { SOURCE } \\
\text { (Abastecer) }\end{array}$ & $\begin{array}{l}\text { Os processos associados ao pedido, entrega, recebimento e transferência } \\
\text { de itens de matérias-primas, subconjuntos, produtos e / ou serviços. }\end{array}$ \\
\hline $\begin{array}{c}\text { MAKE } \\
\text { (fazer) }\end{array}$ & $\begin{array}{l}\text { O processo de agregar valor a uma entrega através da fabricação ou } \\
\text { criação de um produto ou entrega; ou nas indústrias de serviços, criação } \\
\text { de entregas de serviços. }\end{array}$ \\
\hline $\begin{array}{c}\text { DELIVER } \\
\text { (Entregar) }\end{array}$ & $\begin{array}{l}\text { Os processos associados à execução de atividades de gerenciamento de } \\
\text { pedidos e de atendimento de pedidos. }\end{array}$ \\
\hline $\begin{array}{c}\text { RETURN } \\
\text { (Retornar) }\end{array}$ & $\begin{array}{l}\text { Os processos associados à movimentação de material de um cliente de } \\
\text { volta à cadeia de fornecimento para tratar defeitos no produto, pedido ou } \\
\text { fabricação, ou para executar atividades de manutenção. }\end{array}$ \\
\hline $\begin{array}{c}\text { ENABLE } \\
\text { (Habilitar) }\end{array}$ & $\begin{array}{l}\text { Os processos associados ao estabelecimento, manutenção e } \\
\text { monitoramento de informações, relacionamentos, recursos, ativos, regras } \\
\text { de negócios, conformidade e contratos necessários para operar a cadeia } \\
\text { de suprimentos, bem como monitorar e gerenciar o desempenho geral da } \\
\text { cadeia de suprimentos. }\end{array}$ \\
\hline
\end{tabular}

Fonte: Adaptado de APICS (2017)

No segundo nível os processos são segregados basicamente em produtos feitos para estoque, produtos feitos a partir de uma ordem de compra e produtos realizados com base nos requisitos ou especificações de um pedido específico do 


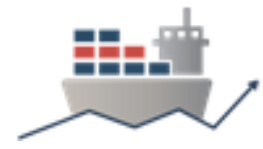

cliente. Nesse é configurado as operações dos agentes, visando descobrir as ineficiências, ou seja, há uma configuração de estratégias de planejamento e execução do fluxo de material de modo a implementar operações estratégicas.

No terceiro nível ocorre a decomposição dos processos em atividades, há um detalhamento de como ocorre todo o processo, levando em conta a habilidade de executar, indicadores e métricas de desempenho, melhores práticas e informações de entrada e saída dos processos. A seguir, os procedimentos metodológicos deste trabalho.

\section{PROCEDIMENTOS METODOLÓGICOS}

Com a finalidade de cumprir o objetivo proposto, esta pesquisa adota uma abordagem qualitativa para identificar e conhecer como é o processo de importação de uma carga conteinerizada. De acordo com Prodanov e Freitas (2013), na abordagem qualitativa o pesquisador necessita de um trabalho intensivo de campo com contato direto com o objeto de estudo, sem qualquer manipulação intencional do mesmo. Sendo os dados coletados do tipo descritivo, pois preocupa-se mais com o processo do que com o produto, assim retrata-se com o maior número de elementos existentes na realidade do estudo.

Para conhecer os agentes envolvidos no processo de importação da carga conteinerizada, neste estudo, o granito prime transportado em um contêiner de $1 \mathrm{TEU}$, houve o contato com o agente trading, Desse modo, os principais agentes envolvidos na importação do granito prime mapeados, são: empresa importadora, que é o cliente do granito prime, a empresa trading, intermediária entre a empresa importadora e os outros agentes, o agente de navegação, o qual realiza contato com o exportador e o armador (dono do navio) e é responsável por acompanhar o trajeto da carga até o porto, o porto, que realiza a operação de descarga do navio e o armazém alfandegado, o qual armazena a carga durante a nacionalização e todo o processo de fiscalização, sendo os dois últimos objetos de estudo desta pesquisa.

Para o desenvolvimento deste artigo foi utilizado o método de estudo de caso, segundo Yin (2001) o estudo de caso é uma investigação empírica de um fenômeno contemporâneo dentro de um contexto da vida real, sendo que os limites entre o fenômeno e o contexto não estão claramente definidos. Nesse contexto, adotou-se para esta pesquisa o estudo de caso único incorporado, que é caracterizado pela investigação de múltiplas unidades que compõem um único caso.

Para a coleta de dados, utilizou-se instrumentos de pesquisa para a realização de entrevistas semiestruturadas, tais instrumentos foram enviados para passar por validação por um agente externo que realiza pesquisas na mesma área. Quando refinados os instrumentos foram enfim usados para condução das entrevistas. Outra precaução tomada para diminuir a influência da subjetividade do pesquisador foi a validação dos dados levantados por parte dos entrevistados. As entrevistas foram conduzidas de modo que de acordo com o diálogo novas perguntas eram realizadas para compreender melhor o processo, cada entrevista durava em torno de 1 hora, sendo gravadas e posteriormente transcritas. A seguir, exemplo do instrumento de pesquisa destinado ao agente porto. 


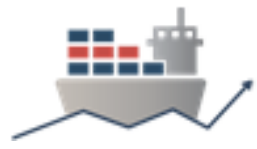

Figura 3 - Instrumento de pesquisa destinado ao porto

\section{Instrumento de pesquisa destinado ao Porto}

Objetivo: Levantar a participação do Porto no processo de importação da carga de granito prime Caracterização de respondente:

Cargo:

Tempo na empresa:

1) Quem faz o primeiro contato com o porto no processo de importação da carga?

2) Qual a responsabilidade do Porto no processo de importação de uma carga de Granito prime? (O que o Porto faz?)

3) Quais os procedimentos realizados pelo porto a partir de seu contato para o processo de importação do Granito prime?

4) Qual a documentação necessária para liberar a atracação do navio com o Granito prime?

5) Qual a documentação necessária para liberar a operação do navio com o Granito prime?

6) Com quais agentes o Porto se relaciona durante o processo de importação do Granito prime? (Em que casos o Porto entra em contato com a empresa, operador e agente de navegação?)

7) Quais são as tarifas que o Porto em questão cobra no processo de importação do Granito prime? (Tarifa aquaviária, terrestre, energia, água, manutenção de balança, silos e armazéns...).

8) Quem realiza o pagamento das tarifas e em que momento se dá esse pagamento ao Porto? (Além disso o pagamento é necessário para a operação do navio e da descarga ou pode ser realizado depois da saída do navio?)

9) Se ocorre algum atraso no desembaraço ou operação e o navio excede o tempo planejado no berço do Porto, o Porto cobra algum tipo de multa pelo tempo excedido? Se sim, a qual agente?

10) Quem são os colaboradores do Porto que têm alguma atuação direta no processo de importação da carga de granito prime?

11) Existe responsabilidade do Porto em caso de danos a carga ou ao navio durante sua permanência no Porto?

12) O Porto disponibiliza algum tipo de armazenagem para a carga do Granito prime? Se sim, a que preço?

Fonte: Adaptado de Medeiros (2018)

Sendo os respondentes destes instrumentos caracterizados no Quadro 3.

Quadro 3 - Caracterização dos entrevistados

\begin{tabular}{|c|c|c|}
\hline \multicolumn{3}{|c|}{ Caracterização dos entrevistados } \\
\hline Agente & Função & Tempo na empresa \\
\hline Trading & Contábil & 2 anos e meio \\
\hline Armazém alfandegado & Analista comercial & 3 anos \\
\hline Porto & Consultor comercial & 1 ano \\
\hline
\end{tabular}

Fonte: Elaborado pelos autores (2019)

Com as informações obtidas pelas entrevistas, realizou-se a análise e foi possível cumprir o objetivo dos instrumentos, de mapear as atividades realizadas por cada agente no processo de importação do granito prime. Assim pôde-se aplicar o modelo SCOR, a fim de alcançar o objetivo de identificar métricas de desempenho na inter-relação dos agentes porto e armazém alfandegado, descrito na Figura 4. 
Figura 4 - Metodologia de aplicação SCOR

Metodologia de aplicação do modelo SCOR

Mapeamento das atividades e compreensão dos processos dos agentes envolvidos

Aplicação do $1^{\circ}$ nível SCOR - Processos (Planejar, Abastecer, Fazer, Entregar, Retornar, Habilitar)

Aplicação do $2^{\circ}$ nível SCOR - Processos (Ordem de compra, ordem para estoque e ordem específicas)

Aplicação do $3^{\circ}$ nível SCOR - Processos (detalhamento das atividades)

Identificação das métricas de desempenho padronizadas.

SCOR - Performance (Métricas)

Fonte: Elaborado pelos autores (2019)

Pode-se visualizar pela Figura 4, que houve 5 etapas básicas para a aplicação do SCOR, sendo o mapeamento das atividades, levantadas pelas entrevistas, a aplicação do primeiro ao terceiro nível do modelo referente aos processos através de uma abordagem qualitativa, e a identificação das métricas fornecidas pela seção de performance do modelo, e que estão correlacionadas com o terceiro nível hierárquico da seção de processos.

\section{RESULTADOS}

\subsection{Descrição da cadeia do produto Granito Prime estudada}

O processo de importação do granito prime inicia-se por meio da empresa importadora, que ao identificar a falta do material, realiza cotações com as empresas exportadoras, localizadas principalmente na China. Ao definir o fornecedor do granito, é efetuado o contato e é repassado todas as informações referentes a carga, para o agente trading, responsável pela gestão da importação do produto, e o agente de carga, responsável pelo transporte marítimo, desde a origem até o porto nacional no Nordeste Brasileiro, através do devido contato com o fornecedor do granito e do armador (proprietário do navio). Sendo uma das principais razões para a contratação da trading, além da gestão de todo o processo de importação, o incentivo fiscal que a mesma possui em relação ao ICMS, reduzindo assim, os custos de importação.

Os principais documentos observados no processo de importação são: invoice (fatura), nota preliminar de venda enviada ao cliente, packing list (guia de remessa), documento que descreve todas as características da carga, bill of lading (BL), é o conhecimento de embarque, ou seja, o contrato de transporte e por último o booking 
(reserva de praça), que é o contrato de reserva de espaço no navio do armador, efetuado pelo agente de carga.

Durante esse processo, o agente trading negocia com o armazém alfandegado quais serviços serão prestados e quais são as características da carga e seus respectivos documentos. No momento que o navio chega na zona primária, ou seja, no porto nacional, e a carga conteinerizada é descarregada, as atividades do agente de carga e do armador encerram-se, e inicia-se a nacionalização da carga por meio da trading. A seguir é descrito as atividades realizadas pelo porto, na zona primária, e pelo armazém alfandegado, na zona secundária, de modo a alcançar o objetivo de identificar métricas de desempenho na inter-relação dos agentes porto e armazém alfandegado.

\subsection{Mapa das atividades executadas pelo armazém alfandegado e porto na cadeia do Granito Prime}

O porto é o agente intermediário nessa cadeia, e inicia suas atividades após o contato com o armador. A seguir as atividades desse agente.

Quadro 4 - Atividades do Porto

\begin{tabular}{|c|c|l|}
\hline $\begin{array}{c}\text { Macro } \\
\text { atividades }\end{array}$ & $N^{\circ}$ & \\
\hline \multirow{4}{*}{$\begin{array}{c}\text { Planejament } \\
\text { o }\end{array}$} & 1 & $\begin{array}{l}\text { Receber dados do navio 48 horas antes da chegada via } \\
\text { armador }\end{array}$ \\
\cline { 2 - 3 } & 2 & Analisar o tempo médio de operação para o navio \\
\cline { 2 - 3 } & 3 & Programar a atracação do navio \\
\cline { 2 - 3 } & 4 & Programar quais equipamentos serão utilizados \\
\cline { 2 - 3 } & 5 & Receber relação de contêineres do Armazém alfandegado \\
\cline { 2 - 4 } & 6 & Planejar o local de armazenagem dos contêineres \\
\hline \multirow{4}{*}{ Operação } & 7 & Atracação do navio \\
\cline { 2 - 3 } & 8 & Retirar contêineres do navio com o portainer \\
\cline { 2 - 3 } & 9 & Transportar contêineres com o transteiner \\
\cline { 2 - 3 } & 10 & Armazenar contêineres no local programado com reach staker \\
\hline \multirow{2}{*}{$\begin{array}{c}\text { Retirar } \\
\text { contêiner }\end{array}$} & 11 & Agendar retirada dos contêineres pelo Armazém alfandegado \\
\cline { 2 - 3 } & 12 & Receber e carregar caminhão do Armazém alfandegado \\
\cline { 2 - 3 } & 13 & Receber contêiner vazio sem avarias \\
\hline
\end{tabular}

Fonte: Autores (2019)

Primeiramente é recebido uma relação dos contêineres e dos tipos de cargas que estão contidas nesses, assim permite um melhor planejamento por parte do porto para a operação de descarga e armazenagem dos contêineres. Outro processo que ocorre antes da atracação do navio, é o recebimento da relação de contêineres que serão retirados pelo armazém alfandegado após a operação de descarga, agilizando o processo de transferência da zona primária para a zona secundária, sendo o principal documento nesse processo, o documento de trânsito de contêiner (DTC). E por fim, a empresa importadora tem o prazo de 30 dias para a devolução do contêiner, caso contrário, ocorre a demurrage, multa relacionada ao atraso da devolução. 
Sendo o equipamento portainer um guindaste especifico para retirada dos contêineres do navio, o transteiner, movimenta a carga até a área de armazenagem e por último o reach staker empilha os contêineres. A seguir as atividades efetuadas pelo armazém alfandegado relacionado a importação do granito prime.

Quadro 5 - Atividades do armazém alfandegado

\begin{tabular}{|c|c|c|}
\hline $\begin{array}{l}\text { Macro } \\
\text { atividades }\end{array}$ & $\mathrm{N}^{\mathrm{O}}$ & Micro atividades \\
\hline \multirow{3}{*}{$\begin{array}{l}\text { Receber } \\
\text { demanda do } \\
\text { cliente }\end{array}$} & 1 & $\begin{array}{l}\text { Receber e-mail com informações sobre a carga e quais serviços } \\
\text { deverão ser prestados }\end{array}$ \\
\hline & 2 & Enviar valor do serviço e negociar pendências \\
\hline & 3 & $\begin{array}{l}\text { Receber e-mail com informações sobre a chegada do navio e } \\
\text { documentações, bill of lading (conhecimento de embarque), } \\
\text { invoice (fatura), packing list (guia de remessa) e conhecimento } \\
\text { eletrônico }\end{array}$ \\
\hline \multirow{9}{*}{$\begin{array}{l}\text { Planejamento } \\
\text { interno }\end{array}$} & 4 & $\begin{array}{l}\text { Verificar se a retirada da carga será documento de trânsito } \\
\text { aduaneiro (DTA) ou em documento de trânsito de contêiner } \\
\text { (DTC) }\end{array}$ \\
\hline & 5 & Fazer controle interno \\
\hline & 6 & Acompanhar no site da zona primária a chegada do navio \\
\hline & 7 & $\begin{array}{l}\text { Enviar para zona primária relação de contêineres e pedir } \\
\text { dispensa do scanner }\end{array}$ \\
\hline & 8 & $\begin{array}{l}\text { Verificar no site da zona primária, a finalização da operação do } \\
\text { navio }\end{array}$ \\
\hline & 9 & Agendar no site da zona primária a retirada dos contêineres \\
\hline & 10 & Programar o carregamento dos contêineres \\
\hline & 11 & Programação de unidades recebidas e quais clientes \\
\hline & 12 & Organização do pátio \\
\hline \multirow{6}{*}{$\begin{array}{l}\text { Transporte do } \\
\text { contêiner }\end{array}$} & 13 & Retirar os contêineres da zona primária para a secundária \\
\hline & 14 & Transporte da carga para zona secundária \\
\hline & 15 & Emissão de ticket pesagem \\
\hline & 16 & Escaneamento do contêiner \\
\hline & 17 & Vistoria do contêiner \\
\hline & 18 & Armazenagem do contêiner \\
\hline \multirow{5}{*}{ Fiscalização } & 19 & $\begin{array}{l}\text { Receber e-mail do cliente pedindo a movimentação do contêiner } \\
\text { para a inspeção do MAPA. }\end{array}$ \\
\hline & 20 & Movimentar contêiner para a área de inspeção \\
\hline & 21 & Aguardar inspeção do MAPA \\
\hline & 22 & Movimentar contêiner para armazenagem \\
\hline & 23 & Aguardar desembaraço do contêiner \\
\hline \multirow{2}{*}{$\begin{array}{c}\text { Agendamento } \\
\text { de retirada }\end{array}$} & 24 & Receber e-mail do cliente para a retirada do contêiner \\
\hline & 25 & Alocar contêiner no caminhão da transportadora \\
\hline
\end{tabular}
Fonte: Autores (2019)

Por escolha da empresa importadora, a nacionalização da carga é realizada no armazém alfandegado, e para isso acontecer, a trading entra em contato com o 
mesmo, de modo que a retirada da carga do porto é feita através do documento de trânsito de contêiner (DTC), assim após a atracação do navio em 48 horas no máximo, o contêiner é transportado da zona primária para a secundária. A principal razão dessa alocação do contêiner é por motivo de menores custos de armazenagem durante a nacionalização.

Após a carga ser transportada para o armazém alfandegado, ocorre a fiscalização da Receita Federal e pelo Ministério da Agricultura, Pecuária e Abastecimento (MAPA), o último é devido à presença de paletes de madeira que apoiam o granito dentro do contêiner. Posteriormente é aguardado a nacionalização da carga efetuada pela empresa importadora, e o agendamento de retirada do granito prime para a mesma através de uma transportadora. A seguir, modelagem do processo entre o armazém alfandegado e porto.

Figura 4 - Elo da cadeia do produto

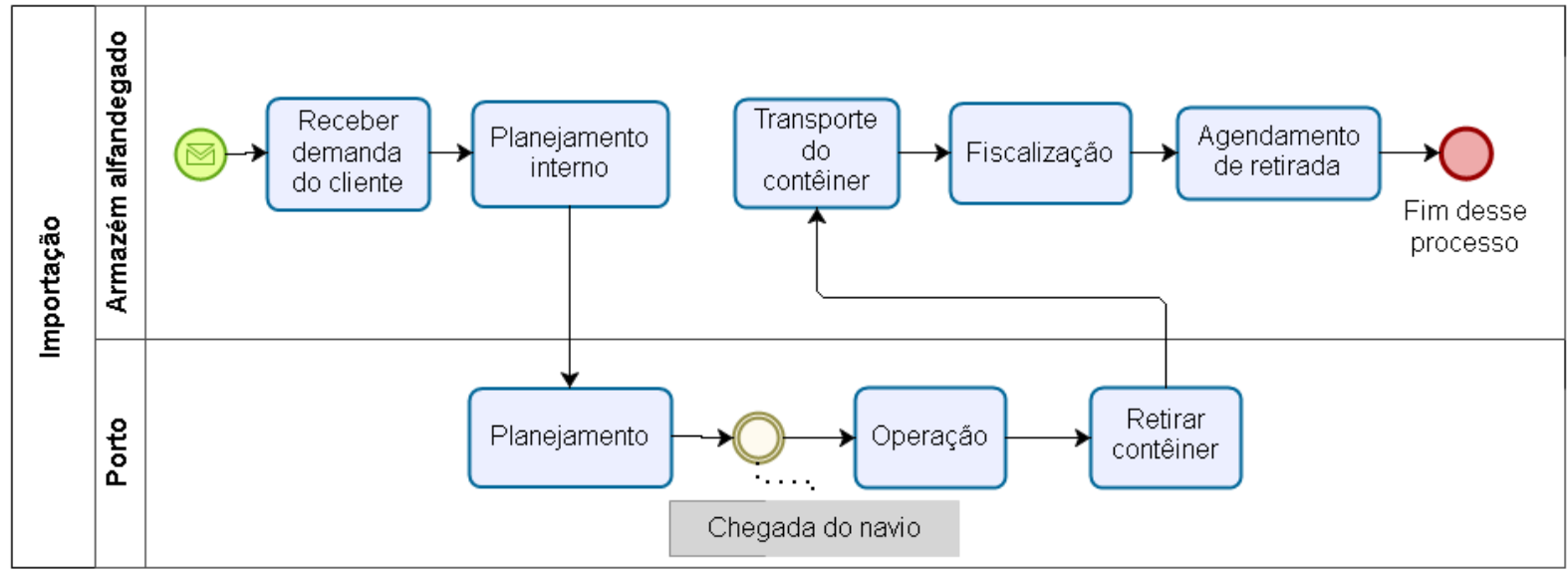

Fonte: Autores (2019)

Como pode-se visualizar, o processo inicia-se através de uma mensagem, nesse caso, por parte da trading, após a negociação, ocorre o planejamento interno. Em seguida, o porto é contatado através da relação de contêineres a serem retirados pelo armazém. Posteriormente a operação do navio, onde a carga é alocada a um pátio, e é armazenada até a sua retirada para a zona secundária. Assim, após o transporte, realiza-se no armazém alfandegado todo o processo de armazenagem, fiscalização e nacionalização da carga de granito prime, até finalmente ser enviada ao cliente final, neste caso, a empresa importadora.

\subsection{Aplicação do modelo SCOR - Processos}

A partir do mapeamento das atividades realizadas pelos agentes dessa cadeia do produto granito prime, especificamente do armazém alfandegado e do porto, podese aplicar do primeiro ao terceiro nível do modelo SCOR referentes a seção de processos. Apresentado a diante.

\subsubsection{Primeiro nível do modelo SCOR - Processos}

Com a compreensão das definições dadas pelo quadro 2 , é definido que as atividades realizadas no processo de importação do granito prime pelos dois agentes citados anteriormente, são partes integrantes dos processos de planejar, fazer e 


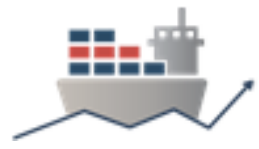

entregar, tal análise é descrita adiante. Sendo que a visualização completa de todas as atividades do armazém alfandegado e porto aplicadas nesses dois processos, estão nos quadros 4 e 5. Do ponto de vista do armazém alfandegado, as atividades como "5-Fazer controle interno" ou "10-Programar o carregamento dos contêineres" são definidas de acordo com o quadro 2, como de planejar, devido ao fato de estarem associadas aos processos de determinação de requisitos para cumprir o objetivo da cadeia logística de importação. Do mesmo modo as atividades que agregam valor ao serviço oferecido pelo armazém alfandegado, como "18-Armazenagem do contêiner" entre outras estão contidas no processo de fazer. Enquanto as atividades relacionadas ao gerenciamento de pedidos, como "3 - Receber e-mail com informações sobre a carga e quais serviços deverão ser prestados" são alocadas no processo de entregar.

Em relação ao porto, o mesmo raciocínio lógico é seguido. No processo de planejar, pode-se alocar a atividade "3 -Programar a atracação do navio". Enquanto no de fazer, atividades que agregam valor pelo serviço oferecido pelo porto, como a atividade "7- Atracação do navio". E finalmente no gerenciamento de pedidos, ou seja, no processo de entrega, por exemplo a atividade "1- Receber dados do navio 48 horas antes da chegada via armador".

Em síntese, as atividades agregadoras de valor, no caso de serviços foram contidas em fazer, as atividades relacionadas ao gerenciamento de pedidos foram identificadas no processo de entregar, e por fim, as atividades relacionadas ao processo de planejamento, no planejar. Esses processos básicos são definidos para melhor compreensão da cadeia logística, e a identificação de quais processos se interrelacionam com outros agentes.

\subsubsection{Segundo nível do modelo SCOR - Processos}

A partir da descrição da cadeia do produto granito prime feita anteriormente, pode-se concluir que do ponto de vista do armazém alfandegado e porto a realização dos serviços prestados por estes se dá pela solicitação de outros agentes, ou seja, a partir de uma ordem de compra. Portanto os processos fazer quanto entregar apresentam como segundo nível a ordem de compra.

O segundo nível do processo de planejar, é apresentado em cinco subníveís, sendo eles: cadeia de suprimentos, abastecimento, fazer, entregar e retornar. Por esse estudo ter mapeado especificamente processos operacionais realizados pelo armazém alfandegado e porto, com o propósito de atender aos requisitos de produção, nesse caso, de serviço, para a importação do granito prime. O segundo nível é definido como o processo de fazer plano (Plan Make), esse definido pela APICS (2017), como ações em certos períodos de tempo que projetam recursos de produção para atender aos requisitos da produção.

Em relação ao segundo nível que no caso é produção por ordem de compra no processo de fazer, é definido pela APICS (2017), como a forma de agregar valor a uma entrega como fabricação ou criação de um produto, nas indústrias de serviços, relacionado a criação de entregas de serviços para um pedido de cliente específico, ou seja, os produtos e serviços são efetuados apenas em resposta a um pedido do cliente.

Enquanto ao processo entregar, o segundo nível que também é por ordem de compra é definido pela APICS (2017), como os processos de fornecimento de produto /serviço fornecidos, configurados, fabricados e / ou montados a partir de matérias- 
primas, peças, ingredientes ou subconjuntos padrão, em resposta a um pedido de cliente específico.

Ao compreender o sistema de produção de cada agente, formado por um conjunto de atividades, que são influenciadas tanto pelo ambiente interno quanto externo, identifica-se a integração desse sistema, ou seja, a integração da zona primária e secundária na cadeia do produto granito prime.

\subsubsection{Terceiro nível do modelo SCOR - Processos}

No terceiro nível do modelo SCOR, o detalhamento é maior, o próprio modelo de acordo com a APICS (2017), fornece um conjunto de descrições predefinidas para as atividades que a maioria das empresas executam de modo a cumprir efetivamente a cadeia de suprimentos. São ações dentro do processo, executadas em uma determinada sequência para planejar, abastecer, fazer, entregar, retornar e habilitar, dentro do contexto do segundo nível, ou seja, no âmbito de sistemas por ordem de compra, ordem para estoque ou pedidos específicos de clientes. Desse modo, para a melhor compreensão deste detalhamento, necessita-se utilizar a nomenclatura fornecida pelo próprio modelo e apresentada a seguir.

Tabela 1 - Legenda dos níveis utilizados do modelo SCOR

\begin{tabular}{cl}
\hline & \multicolumn{2}{c}{ Primeiro Nível } \\
\hline SP & Plan (Planejar) \\
sM & Make (Fazer) \\
sD & Deliver (Entregar) \\
\hline & \multicolumn{1}{c}{ Segundo Nível } \\
\hline sP3 & Plan Make (Fazer plano) \\
sM2 & Make-to-Order (Fazer por ordem de compra) \\
sD2 & Deliver Make-to-Order Product (Entregar produto por ordem de compra) \\
\hline & \\
\hline sP3.3 & Balancear os recursos de produção com requisitos de produção \\
sM2.1 & Agendar atividades de produção \\
sM2.2 & Emitir produto da origem para processo \\
sM2.3 & Produção e Teste \\
sM2.6 & Liberar produto acabado para entregar \\
sD2.1 & Processo de pedidos e cotações \\
sD2.2 & Receber, configurar, inserir e validar o pedido \\
sD2.12 & Enviar produto \\
sD2.15 & Fatura \\
\hline$\left(^{*}\right)$ & s significa SCOR \\
\hline
\end{tabular}

Fonte: Elaborado pelos autores (2019)

$\mathrm{Na}$ tabela 1, é apresentado as nomenclaturas do primeiro e segundo nível explicados em seções anteriores, e do terceiro nível, este mostra descrições de atividades predefinidas pelo modelo, pois entende-se que tais atividades são, na maioria, executadas por grande parte das empresas para cumprir a cadeia de suprimentos, neste caso do produto granito prime. Por exemplo, a atividade de "Produção e Teste" nesta pesquisa entende-se como a etapa que caracteriza o serviço principal oferecido pelo agente de importação. Assim é possível resumir o 
procedimento de cada etapa da aplicação do modelo SCOR, de modo a compará-las e compreender o detalhamento das atividades do armazém alfandegado e do porto, nos processos do terceiro nível. Apresentados a seguir.

Quadro $6-3^{\circ}$ nível aplicado nas atividades do armazém alfandegado

\begin{tabular}{|c|c|}
\hline 3Nível & Atividades do armazém alfandegado \\
\hline \multirow{4}{*}{ sP3.3 } & 5-Fazer controle interno \\
\hline & 6-Acompanhar no site da zona primária a chegada do navio \\
\hline & 10-Programar o carregamento dos contêineres \\
\hline & 11-Programação de unidades recebidas e quais clientes \\
\hline \multirow{4}{*}{ sM2.1 } & $\begin{array}{l}\text { 7-Enviar para zona primária relação de contêineres e pedir dispensa do } \\
\text { scanner }\end{array}$ \\
\hline & 8-Verificar no site da zona primária, a finalização da operação do navio \\
\hline & 9-Agendar no site da zona primária a retirada dos contêineres \\
\hline & 12-Organização do pátio \\
\hline \multirow{2}{*}{ sM2.2 } & 13-Retirar contêineres da zona primária para a secundária \\
\hline & 14-Transporte da carga para zona secundária \\
\hline \multirow{7}{*}{ sM2.3 } & 15-Emissão de ticket pesagem \\
\hline & 16-Escaneamento do contêiner \\
\hline & 17-Vistoria do contêiner \\
\hline & 18-Armazenagem do contêiner \\
\hline & 20-Movimentar contêiner para a área de inspeção \\
\hline & 21-Aguardar inspeção do MAPA \\
\hline & 22-Movimentar contêiner para armazenagem \\
\hline sM2.6 & 23-Aguardar desembaraço do contêiner \\
\hline \multirow{2}{*}{ sD2.1 } & $\begin{array}{l}\text { 1-Receber e-mail com informações sobre a carga e quais serviços } \\
\text { deverão ser prestados }\end{array}$ \\
\hline & $\begin{array}{l}\text { 19- Receber e-mail do cliente pedindo a movimentação do contêiner para } \\
\text { a inspeção do MAPA. }\end{array}$ \\
\hline \multirow{3}{*}{ sD2.2 } & $\begin{array}{l}\text { 3-Receber e-mail com informações sobre a chegada do navio e } \\
\text { documentações, bill of lading (conhecimento de embarque), invoice } \\
\text { (fatura), packing list (guia de remessa) e conhecimento eletrônico }\end{array}$ \\
\hline & $\begin{array}{l}\text { 4-Verificar se a retirada da carga será por meio do documento de trânsito } \\
\text { aduaneiro (DTA) ou por meio do documento de trânsito de contêiner } \\
\text { (DTC) }\end{array}$ \\
\hline & 24-Receber e-mail do cliente para a retirada do contêiner \\
\hline sD2.12 & 25-Alocar contêiner no caminhão da transportadora \\
\hline sD2.15 & 2-Enviar valor do serviço e negociar pendências \\
\hline
\end{tabular}

Fonte: Elaborado pelos autores (2019)

Quadro $7-3^{\circ}$ nível aplicado nas atividades do porto

\begin{tabular}{|c|l|}
\hline 3Nível & \multicolumn{1}{|c|}{ Atividades porto } \\
\hline \multirow{3}{*}{ sP3.3 } & 3-Programar a atracação do navio \\
\cline { 2 - 2 } & 4-Programar quais equipamentos serão utilizados \\
\cline { 2 - 2 } & 6-Planejar o local de armazenagem dos contêineres \\
\hline sM2.1 & 10-Agendar retirada dos contêineres pelo armazém alfandegado \\
\hline sM2.3 & 7-Retirar contêineres do navio com o portainer \\
\hline
\end{tabular}




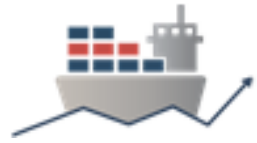

\begin{tabular}{|c|l|} 
& 8-Transportar contêineres com o transteiner \\
\cline { 2 - 3 } & 9-Armazenar contêineres no local programado com reach staker \\
\hline \multirow{2}{*}{ sD2.1 } & 1-Receber dados do navio 48 horas antes da chegada via Armador \\
\cline { 2 - 3 } & 5-Receber relação de contêineres (DTC) do Armazém alfandegado \\
\hline sD2.2 & 2-Analisar o tempo médio de operação para o navio \\
\hline \multirow{2}{*}{ sD2.12 } & 11-Receber e carregar caminhão do Armazém alfandegado \\
\cline { 2 - 3 } & 12-Receber contêiner vazio sem avarias \\
\hline
\end{tabular}

Fonte: Elaborado pelos autores (2019)

Por meio da identificação das atividades realizadas pelos agentes com as atividades que o modelo oferece, pode-se identificar gaps na cadeia do produto granito prime, especificamente na relação entre o armazém alfandegado e o porto. $O$ terceiro nível do SCOR apresenta um detalhamento dos processos do segundo nível apresentado, assim permite-se agregar informações sobre o processo, de modo a investiga-los através das métricas de desempenho apresentados na próxima seção.

\subsection{Métricas de desempenho por processos}

As métricas possuem o propósito de medir o desempenho dos processos e são a base que permite analisar a causa de problemas, os gaps. Ao identificar as atividades no terceiro nível de processos do modelo SCOR, o mesmo sugere métricas de desempenho, ao utilizar tais métricas padronizadas em ambos agentes da cadeia do produto, pode-se compará-las para uma possível melhoria do sistema como um todo.

Quadro 8 - Métricas por atividades - SCOR

\begin{tabular}{|c|c|c|}
\hline Relação & $3^{\circ}$ Nível de Processos & Métricas aplicáveis as atividades \\
\hline sP3.3 & $\begin{array}{l}\text { Balancear os recursos de } \\
\text { produção com requisitos de } \\
\text { produção }\end{array}$ & $\begin{array}{l}\text { Balancear os recursos de produção com o } \\
\text { tempo de ciclo dos requisitos de produção }\end{array}$ \\
\hline \multirow{3}{*}{ sM2.1 } & \multirow{3}{*}{$\begin{array}{l}\text { Agendar atividades de } \\
\text { produção }\end{array}$} & Atingir cronograma de produção \\
\hline & & $\begin{array}{l}\text { Programar tempo de ciclo de atividades de } \\
\text { produção }\end{array}$ \\
\hline & & $\begin{array}{l}\text { Medir a capacidade de utilização de um } \\
\text { recurso }\end{array}$ \\
\hline sM2.2 & $\begin{array}{l}\text { Emitir produto da origem } \\
\text { para processo }\end{array}$ & $\begin{array}{l}\text { Medir tempo de ciclo do produto da origem } \\
\text { para processo }\end{array}$ \\
\hline \multirow{3}{*}{ sM2.3 } & \multirow{3}{*}{ Produção e Teste } & Estimar variabilidade de produção \\
\hline & & Produzir e testar o tempo de ciclo \\
\hline & & $\begin{array}{l}\text { Medir a capacidade de utilização de um } \\
\text { recurso }\end{array}$ \\
\hline sM2.6 & $\begin{array}{l}\text { Liberar produto acabado } \\
\text { para entregar }\end{array}$ & $\begin{array}{l}\text { Medir tempo de ciclo para liberar produto } \\
\text { acabado para entrega }\end{array}$ \\
\hline sD2.1 & $\begin{array}{l}\text { Processo de pedidos e } \\
\text { cotações }\end{array}$ & $\begin{array}{l}\text { Calcular custos de gerenciamento de } \\
\text { pedidos }\end{array}$ \\
\hline \multirow{3}{*}{$\mathrm{sD} 2.2$} & \multirow{3}{*}{$\begin{array}{l}\text { Receber, configurar, inserir } \\
\text { e validar o pedido }\end{array}$} & Avaliar precisão do Item de Entrega \\
\hline & & \\
\hline & & Avaliar precisão da quantidade de ent \\
\hline
\end{tabular}




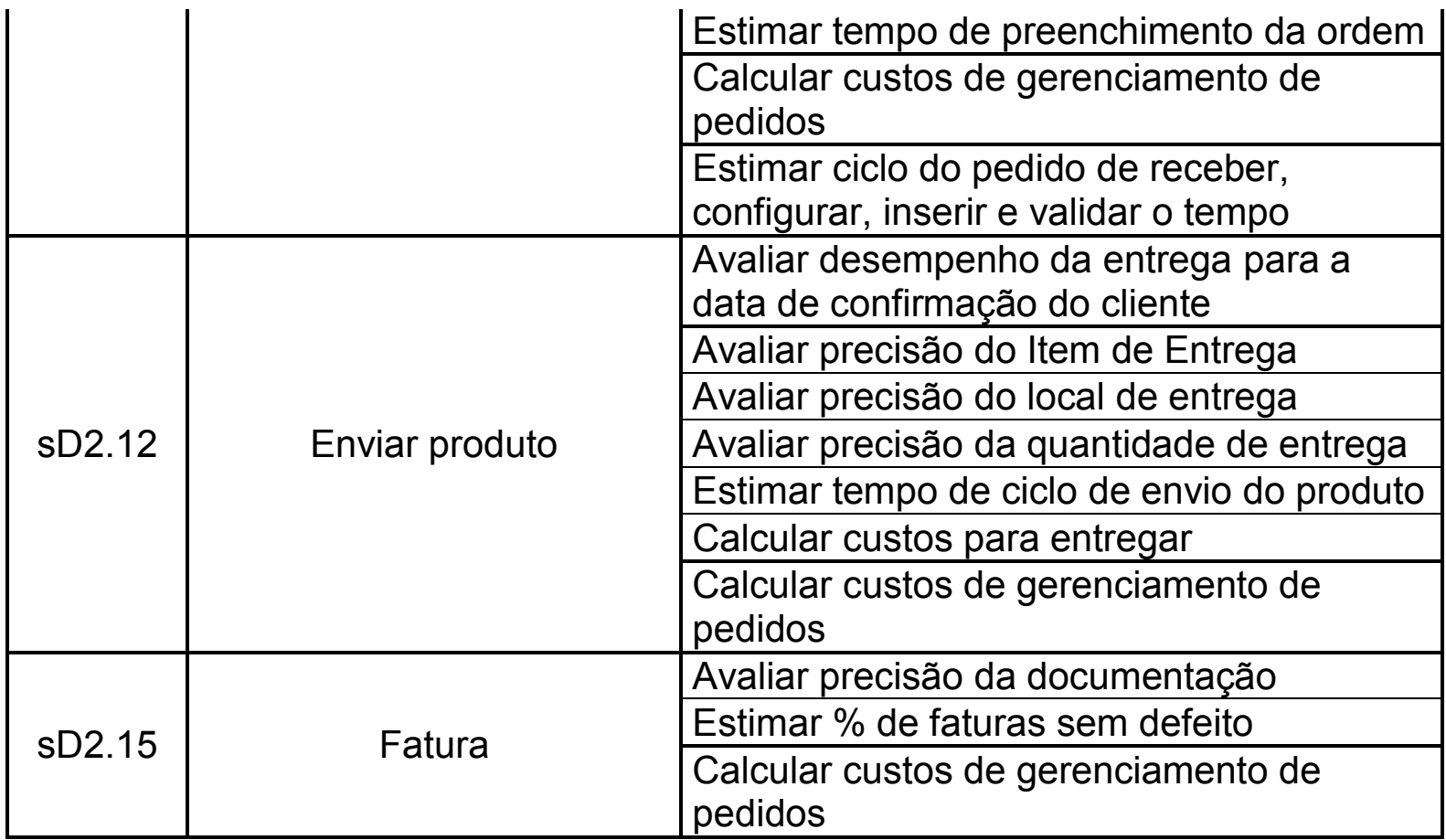

Fonte: Elaborado pelos autores (2019)

No quadro a seguir é explicado detalhadamente cada métrica, a partir das descrições fornecidas pelo modelo SCOR.

Quadro 9 - Descrição das métricas

\begin{tabular}{|l|l|}
\hline \multicolumn{1}{|c|}{ Métricas aplicáveis ao processo } & \multicolumn{1}{|c|}{ Descrição das métricas } \\
\hline $\begin{array}{l}\text { Balancear os recursos de produção } \\
\text { com o tempo de ciclo dos requisitos de } \\
\text { produção }\end{array}$ & $\begin{array}{l}\text { O tempo médio associado à identificação, } \\
\text { priorização e agregação de requisitos do } \\
\text { produto. }\end{array}$ \\
\hline Atingir cronograma de produção & $\begin{array}{l}\text { A porcentagem de tempo que uma } \\
\text { empresa atinge seu cronograma de } \\
\text { produção (Neste caso de serviço). }\end{array}$ \\
\hline $\begin{array}{l}\text { Programar tempo de ciclo de atividades } \\
\text { de produção }\end{array}$ & $\begin{array}{l}\text { O tempo médio associado ao } \\
\text { agendamento de produção (serviço). }\end{array}$ \\
\hline $\begin{array}{l}\text { Medir a capacidade de utilização de um um } \\
\text { recurso }\end{array}$ & $\begin{array}{l}\text { Uma medida de quão intensivamente um } \\
\text { recurso está sendo usado para produzir } \\
\text { um bom serviço. }\end{array}$ \\
\hline $\begin{array}{l}\text { Medir tempo de ciclo do produto da } \\
\text { origem para processo }\end{array}$ & \begin{tabular}{l} 
O tempo de envio do produto. \\
\hline Estimar variabilidade de produção
\end{tabular} \\
$\begin{array}{l}\text { A condição que ocorre quando a saída de } \\
\text { um processo não é consistentemente } \\
\text { repetível em quantidade, qualidade ou } \\
\text { combinação destes. }\end{array}$ \\
\hline Produzir e testar o tempo de ciclo & $\begin{array}{l}\text { O tempo médio de produção (serviço) e } \\
\text { teste. }\end{array}$ \\
\hline $\begin{array}{l}\text { Medir tempo de ciclo para liberar produto } \\
\text { acabado para entrega }\end{array}$ & $\begin{array}{l}\text { O tempo médio associado à liberação do } \\
\text { produto acabado para entregar. }\end{array}$ \\
\hline
\end{tabular}


VI CIDESPORT/2019

Congresso Internacional

de Desempenho Portuário

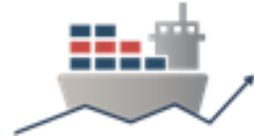

\begin{tabular}{|c|c|}
\hline $\begin{array}{l}\text { Calcular custos de gerenciamento de } \\
\text { Jedidos }\end{array}$ & $\begin{array}{l}\text { A agregação dos elementos de custo, por } \\
\text { exemplo: Custo para receber o produto; } \\
\text { Custo para agendar entregas de produtos; } \\
\text { Custo para transferir produto; Custo de } \\
\text { mão de obra direta; entre outros. }\end{array}$ \\
\hline Avaliar precisão do Item de Entrega & $\begin{array}{l}\text { Porcentagem de pedidos em que todos os } \\
\text { itens são realmente fornecidos e nenhum } \\
\text { item extra é fornecido }\end{array}$ \\
\hline Avaliar precisão do local de entrega & $\begin{array}{l}\text { Porcentagem de pedidos que são } \\
\text { entregues no local correto }\end{array}$ \\
\hline $\begin{array}{l}\text { Avaliar precisão da quantidade de } \\
\text { entrega }\end{array}$ & $\begin{array}{l}\text { Porcentagem de pedidos em que todas as } \\
\text { quantidades são recebidas pelo cliente. }\end{array}$ \\
\hline $\begin{array}{l}\text { Estimar tempo de preenchimento da } \\
\text { ordem }\end{array}$ & $\begin{array}{l}\text { Quando é imposto pelos requisitos do } \\
\text { cliente? Esse tempo de espera é diferente } \\
\text { do tempo ocioso ou do lead time sem valor } \\
\text { agregado, que é causado por ineficiências } \\
\text { na organização e nos processos. }\end{array}$ \\
\hline $\begin{array}{l}\text { Estimar ciclo do pedido de receber, } \\
\text { configurar, inserir e validar o tempo }\end{array}$ & $\begin{array}{l}\text { O tempo médio associado ao recebimento } \\
\text { e verificação de um pedido no site do } \\
\text { cliente }\end{array}$ \\
\hline $\begin{array}{l}\text { Avaliar desempenho da entrega para a } \\
\text { data de confirmação do cliente }\end{array}$ & $\begin{array}{l}\text { A porcentagem de pedidos que são } \\
\text { atendidos na data de confirmação do } \\
\text { cliente. }\end{array}$ \\
\hline $\begin{array}{l}\text { Estimar tempo de ciclo de envio do } \\
\text { produto }\end{array}$ & $\begin{array}{l}\text { O tempo médio associado ao envio do } \\
\text { produto. }\end{array}$ \\
\hline Calcular custos para entregar & $\begin{array}{l}\text { A soma dos custos associados ao } \\
\text { processo de entregar. }\end{array}$ \\
\hline Avaliar precisão da documentação & $\begin{array}{l}\text { Porcentagem de pedidos, incluindo guias } \\
\text { de embalagem, conhecimentos de } \\
\text { embarque, faturas etc. }\end{array}$ \\
\hline Estimar $\%$ de faturas sem defeito & $\begin{array}{l}\text { O número de faturas processadas pelo } \\
\text { número total de faturas. Exemplos de } \\
\text { possíveis defeitos na fatura são: } \\
\text { Informações incorretas do cliente, } \\
\text { informações erradas sobre o produto, } \\
\text { preço incorreto, quantidade incorreta ou } \\
\text { termos incorretos ou data incorreta. }\end{array}$ \\
\hline
\end{tabular}

Fonte: Adaptado de APICS (2017)

Portanto, com a identificação das métricas de desempenho pode-se analisar de modo padronizado os gaps na inter-relação do armazém alfandegado e o porto, de modo a diagnosticar tendências e comportamentos. Por exemplo a atividade "sM2.1 - Agendar atividades de produção", este possui três métricas, que pode-se observar no Quadro 7, dentre estas, a métrica "Programar tempo de ciclo de atividades de produção", corresponde no contexto do porto e do armazém alfandegado, o agendamento de retirada da carga conteinerizada da zona primária para a secundária, desse modo ao utilizarem uma métrica padronizada, disponibiliza-se ao gestores uma análise de forma simples e prática em respeito a esse processo, sendo estes responsáveis por ações corretivas ou de otimização do processo. 


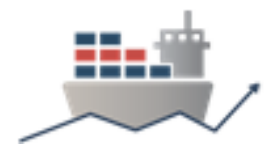

\section{CONSIDERAÇÕES FINAIS}

O mapeamento da cadeia do produto Granito Prime iniciou-se por um agente intermediário, a trading, isto permitiu que a maior parte do processo da cadeia do produto e seus principais agentes fossem identificados. Este agente oferece serviços de modo a facilitar o processo de importação, supervisiona e age desde a saída da carga do exterior, até o transporte terrestre para o cliente final.

O porto atua como zona primária, realizando somente atividades relacionadas a retirada do contêiner do navio e posteriormente transferindo-a para zona secundária, o armazém alfandegado. Assim todo o processo de nacionalização da carga, fiscalização e armazenamento ocorre enquanto a carga está no armazém alfandegado, após este processo ocorre somente o transporte para o cliente final.

Com este levantamento foi possível identificar que o maior empecilho na importação, são erros na documentação, pois se ocorrer alguma inconsistência nos documentos de invoice (fatura), packing list (guia de remessa) ou bill of lading (conhecimento de embarque), os órgãos anuentes, principalmente a Receita Federal, indicam "canal laranja" ou "canal vermelho" no processo de nacionalização, requerendo assim uma vistoria minuciosa dos documentos e da carga.

Com a aplicação da abordagem logística, o SCOR, nas atividades realizadas pelo armazém alfandegado e o porto, foi possível estruturar melhor as mesmas, de modo a compreender quais tarefas compõe no gerenciamento de pedidos, agregação de valor por meio da criação ou entrega de serviços, planejamento e relacionado ao recebimento de matéria-prima ou serviço. Por meio do segundo nível, compreende-se o sistema de produção do agente, há uma configuração de estratégias e ações a respeito do fluxo de material de modo a implementar operações estratégicas. E pelo terceiro nível, há o detalhamento de como ocorre todo o processo, cada atividade realizada é descrita. O modelo SCOR facilita a enxergar a cadeia de suprimentos e a comunicação entre os membros do mesmo, assim atribuindo-se métricas.

A atribuição de métricas é um padrão para medir o desempenho de uma cadeia de suprimentos ou processo. As métricas do SCOR são métricas de diagnóstico, que permitem ao gestor identificar de modo simples e prático gargalos nos processos definidos no Quadro 2. A aplicação destas métricas no contexto portuário, deve-se ao fato do crescente comércio internacional, e da importância tanto as zonas primárias quanto secundárias, para a economia regional e nacional, tanto no processo de importação quanto no processo de exportação.

A competitividade do mercado exige que as empresas tenham um olhar atento a gestão de custos, de modo a melhorar a eficiência dos processos. No caso da cadeia do produto, com o conhecimento de seus agentes e características, é possível mapear todos os processos envolvidos. Assim sugere-se para trabalhos futuros a aplicação do modelo SCOR com uma abordagem de natureza quantitativa, de modo a mensurar todo o processo e além disso utilizar as informações encontradas para um posicionamento estratégico.

\section{REFERÊNCIAS}

ANTAQ, Agência Nacional De Transportes Aquaviários. ANTAQ divulga os números da movimentação portuária de 2018. 2019. Disponível em: < http://portal.antaq.gov.br/index.php/2019/02/12/antaq-divulga-os-numeros-damovimentacao-portuaria-de-2018/>. Acesso em: 15 de julho de 2019. 
VI CIDESPORT/2019

Congresso Internacional

de Desempenho Portuário

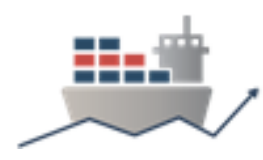

APICS. Supply chain reference model - SCOR. Versão 12.0. 2017.

ALVAREZ-SANJAIME, O. et al. Competition and horizontal integration in maritime freight transport. Transportation Research Part E-Logistics and Transportation Review, v. 51, p. 67-81, 2013.

ALVAREZ-SANJAIME, O. et al. The impact on port competition of the integration of port and inland transport services. Transportation Research Part B Methodological, V. 80, p. 291-302, 2015.

Astuti, R.; Sililahi, R. L. R.; Rosyadi, R. A. Risk Mitigation Strategy for Mangosteen Business Using House of Risk (HOR) Methods: (A Case Study in "Wijaya Buah", Blitar District, Indonesia). 3rd International Conference on Agro-Industry 2016 "Competitive \& Sustainable Agro-Industry: Value Creation in Agribusiness". 2016.

Anggrahini, D.; Karningsih, P. D.; Sulistiyono, M. Managing quality risk in a frozen shrimp supply chain : a case study. Industrial Engineering and Service Science. 2015, IESS 2015.

Bukhori, I. B.; Widodo, K. H.; Ismoyowati, D. Evaluation of Poultry Supply Chain Performance in XYZ Slaughtering House Yogyakarta using SCOR and AHP Method. The 2014 International Conference on Agro-industry (ICoA) : Competitive and sustainable Agroindustry for Human Welfare. 2015.

$\mathrm{CHO}, \mathrm{H}$. S. Determinants and effects of logistics costs in container ports: The transaction cost economics perspective. Asian Journal of Shipping and Logistics, v. 30, n. 2, p. 193-215, 2014.

CLOTT, C.; HARTMAN, B. C. Supply chain integration, landside operations and port accessibility in metropolitan Chicago. Journal of Transport Geography, V. 51, p. 130-139, 2016.

CANON, P.; FERRARI, C.; PAROLA, F. Strategies in maritime and port logistics. Maritime Economics \& Logistics, v. 17, n. 1, p. 1-8, 2015.

CASCHILI, S.; MEDDA, F. The port attractiveness index: application on African ports. Region et Developpement, n. 41, p. 47-82, 2015.

CSCMP, Council of Supply Chain Management Professionals. Supply chain management definitions and glossary. 2013. Disponível em:<https://cscmp.org/CSCMP/Educate/SCM_Definitions_and_Glossary_of_Terms/ CSCMP/Educate/SCM_Definitions_and_Glossary_of_Terms.aspx?hkey=60879588f65f-4ab5-8c4b-6878815ef921>. Acesso em: 24 de agosto de 2019.

KE, W. The Empirical Research on Enterprise Logistics Cost Based on Activity Based Cost. Proceedings of the 2014 International Conference on Mechatronics, Control and Electronic Engineering. [s.l: s.n.]. v. 113p. 538-541.

KRASNODĘBSKI, A.; KUBON, M. Logistic costs in competitive strategies of enterprises. Agricultural Economics, Czech, 56, 2010 (8): 397-402.

LEITE, M. A. S.; VASCONCELOS, V. M. M.; BORNIA, A. C.; AFONSO, P. S. L. P.; ARAÚJO, A.; TELHADA, J. M.; MONTEIRO, L. M. Discussão de um modelo conceitual 


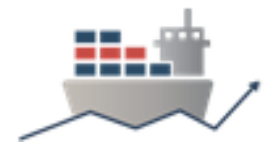

para gestão de custos logísticos no setor portuário: os casos português e brasileiro. Medellín. Ln: XIV Congresso Internacional de Custos, 2015.

LIN, D. P. et al. Impact of Policy Adjustment on the Port Performance: the Case of Shanghai Port. In: Zhang Z., Shen Z., Zhang J., Zhang R. (eds) LISS 2014. Springer, Berlin, Heidelberg, 2015.

MILAN, G. S.; VIEIRA, G. B. B. Proposição de um modelo conceitual em torno da prática da governança em cadeias logístico-portuárias. Revista Gestão Industrial, Paraná, v. 7, n. 4, 2011.

MOREIRA, G. G.; SILVA, J. F.; LEITE, M. S. A. Discussão acerca dos agentes envolvidos no processo de aquisição, desembaraço e operação com cargas de trigo em um porto público do Nordeste. IV Congresso Internacional de Desempenho Portuário. Florianópolis, Santa Catarina, 2017.

MEDEIROS, M. Mensuração dos custos logísticos em uma operação com carga sólida em um porto público do nordeste brasileiro. 2018. 220f. Dissertação de Mestrado - Universidade Federal da Paraíba, João Pessoa, 2018.

OJADI, F.; WALTERS, J. Critical factors that impact on the efficiency of the Lagos seaports. Journal of Transport and Supply Chain Management, v. 9, n. 1, p. 1-13, 2015.

PRODANOV, C. C.; FREITAS, E. C. de. Metodologia do trabalho científico: métodos e técnicas da pesquisa e do trabalho acadêmico. 2. ed. Novo Hamburgo: Feevale, 2013.

PONTES, T. N.; CORREA, E. V. T.; BRITO, A.; PEREIRA, D.; Análise de processos de uma distribuidora a partir do modelo SCOR. XXXVIII Encontro Nacional de Engenharia de Produção. Macéio, Alagoas, 2018.

SILVA, J. F.; MOREIRA, G. G.; LEITE, M. S. A. Análise qualitativa do uso dos recursos empregados no processo de descarga de granel sólido em um porto público do Nordeste (BR). V Congresso internacional de desempenho portuário. Florianópolis, Santa Catarina, 2018.

SANTOS, W. A.; VILLAVICENCIO, G. D. Gestão logística: o caso da empresa "Santos brasil". Revista Orbis Latina, Paraná, v. 8, n. 1, 2018.

SONG, D. W.; PANAYIDES, P. M. Maritime Logistics: A Guide to Contemporary Shipping and Port Management. Kogan Page, p. 480, 2015.

SOUZA, R. DA S.; SOUZA, G. DA S. A Logística Internacional e Comércio Exterior Brasileiro: Modais de Transporte, Fluxos Logísticos e Custos Envolvidos. Simpósio De Excelência Em Gestão E Tecnologia. Anais...2013.

SPINA, M. E.; ROHVEIN, C.; URRUTIA, S.; ROARK, G.; PARAVIÉ, D.; CORRES, G. Application of the SCOR model in metalworking SMEs from Olavarría. INGE CUC, vol. 12 no. 2 , pp 50-57. 2016.

SILVA, J. F. Proposta de etapas para sistematização dos custos da cadeia logística de importação de cargas sólidas escoadas em Portos do NE do Brasil. Relatório de Iniciação Científica. Universidade Federal da Paraíba. 2019.

SILVA, S. F. N.; LISBOA, A. P.; JESUS, W. S.; SILVA, I. P.; VASCONCELOS, C. R; $O$ modelo de referência SCOR como ferramenta para a gestão da cadeia de 
VI CIDESPORT/2019

Congresso Internacional

de Desempenho Portuário

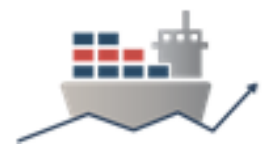

suprimentos: Uma aplicação em uma loja de serviços. Simpósio de Engenharia de Produção de Sergipe. São Cristóvão, SE, 2015.

UNCTDA, United Nations Conference on Trade and Development; Informe sobre el transporte marítimo, 2018.2 Disponível em: <https://unctad.org/es/PublicationsLibrary/rmt2018_es.pdf>. Acesso em: 24 de agosto 2019.

YIN, R. K. Estudo de caso: planejamento e métodos. 2 ed. Porto Alegre:Bookman, 2001. 